\title{
Corporate Social Responsibility: Theoretical Discussions
}

\author{
Yezdi H. Godiwalla ${ }^{1}$ \\ ${ }^{1}$ College of Business and Economics, University of Wisconsin-Whitewater, Whitewater, WI, USA. \\ Correspondence: Yezdi H. Godiwalla, Management Department, College of Business and Economics, University of \\ Wisconsin-Whitewater, Whitewater, WI 53190-1790, USA.
}

Received: February 17, 2016

Accepted: February 26, 2016

Available online: March 1, 2016

doi:10.11114/ijsss.v4i4.1428

URL: http://dx.doi.org/10.11114/ijsss.v4i4.1428

\begin{abstract}
Organizations, as integral parts of a society, must conduct themselves with the higher standards of legality, ethics, decency and corporate citizenship. This is to exceed the higher expectations of a given society. The modern day rapidity of social media and journalism, together with widespread global scope, make it necessary for organizations to be ever so vigilant, careful in their conduct. It calls for increasing standards of internal communication and training so that their employees meet and exceed the rising societal and stakeholder expectations. In the case of an MNC or global organization, the social responsibilities goals and strategies would depend upon a foreign subsidiary's host country needs and expectations, and, overall MNC's and foreign unit's resource capabilities. This issue is important in determining the sustainability and scope of social responsibilities goals and strategies. The stakeholder approach is important. Stakeholders of the MNC as a whole, and, those of each foreign subsidiary unit are together important in this regard.
\end{abstract}

Keywords: Corporate social responsibility, corporate social responsibility theoretical discussions.

\section{Introduction}

\subsection{Introductory Issues and the Relevance of Social Responsibility}

Corporate Social Responsibility has become a pervasive topic in business literature and also is getting very important in business management. Today, modern business organizations have to be more mindful of all its stakeholders and the general public, compared to what their counterparts have done only half century ago. Stockholders are no longer the only important stakeholder and the only object of the management of an organization, particularly if the organization is a large global or multinational corporation (MNC).

Corporate social responsibility (CSR) expectations are continuously rising. Globally or domestically oriented organizations are not only expected to produce quality products and exceed investor expectations, they are also expected to exceed the public and stakeholder expectations. These expectations, which are ever-rising, are for the organizational conduct for: legal, ethical, economics, decent or honorable, and philanthropic activities. These expectations are even more sensitive for global or MNCs.

Corporate Social Responsibility (CSR) has become a quite pervasive topic in business literature. Although, historically, the prevailing notion of CSR was embedded in liberal market economies with the defeat of social solidarity, today organizations are seen as integral parts of a society and they must conduct themselves with the higher standards of legality, ethics, decency and corporate citizenship, thus CSR comes to the fore. Furthermore, today the rapidity of modern social media and journalism, together with widespread global scope, make it necessary for organizations to be vigilant and careful in their conduct. This new situation calls for increasing standards of internal communication and training so that the employees of organizations meet and exceed the rising societal and stakeholder expectations. This paper analyzes the theoretical discussions upon CSR, although not in an exhaustive manner, and tries to suggest recommendations for organization's actions

The management of organizations has to communicate, train and oversee ethical and decent or honorable behavior of the employee's actions as they may affect the perceptions of the public and the stakeholders. As the rapidly responsive global social media and journalism closely looks at the corporate conduct, organizations must be ever so vigilant in planning and executing decisions.

Society seriously holds organizations accountable for their conduct as a matter of a trust issue. If they lose the society's 
trust, they may also lose their business. They must simultaneously compete and be highly ethical, and decent or honorable, and socially responsible to keep earning the trust. Religion often plays a strong role in the development of a society's cultural and business values and ethics (Ali and Al-Aali, 2015; Duska, 2014; Tlaiss, 2015).

\subsection{Background Events and Considerations}

The widespread shock and strong protest from the public and government after the severe 2008-2010 U.S. financial meltdown again reminded the public that executive recklessness and excess can dramatically destroy the lives of the many. The public and the stakeholder expectations include prudent and careful strategic and operation decision making and execution. Responsible business decision making and action are the warning watch words for management and employees. These are again the reminders of the severe 2008-2010 U.S. financial meltdown and its consequences.

These 2008-2010 events have required the swift and drastic governmental intrusive corrective actions that reactively re-set the U.S. free market system. The focused corrective actions by the government substituted organizations executive decision making and managerial action. One is reminded of the magnitude of the requisite governmental intrusive corrective action that followed the 1930s Great Depression. Corporations need to be periodically reminded of the need for ever greater vigilance and for more responsible risk taking to deal with the vicissitudes in the external environment. Although there have been significant regulatory oversight since the 1930s, even so, there should be an organizational attempt to better govern itself. There should be a well-designed and well-administered organizational process. They should reflect a high quality of self-disciplined and self-monitored corporate decision making process and corporate conduct that enhances ethical and responsible corporate performance.

Elective governmental officials and society have a more direct closeness, while appointed governmental civil servants follow extant laws, statutes, rules, policies and precedents in reigning in aberrations of corporate conduct (Alzola, 2015). These governmental and public concerns and awareness have been targeted across many industries, across manufacturing and service sectors, in auto industry and in sectors of retailing, banking, mortgage, investment and insurance. Since the meltdown the government and public have strongly espoused the instilling into corporations prudent judgment, the curtailment of their greed, and, the strong self-discipline and self-refrain to avoid the repetition of the reckless business decision making and behavior. These events since the meltdown have led to widespread public demand for better oversight and control to curb any wrong doing, greed, grossly irresponsible actions or reckless judgments.

\subsection{Corporate Governance and Social Responsibility}

As stewarts of business organizations, the managements of business organizations are charged with its economic performance and exceed investor expectations in a manner consistent with societal values and expectations of corporate conduct. Pressures on governmental officers for identifying possible fraud or other illegal, unethical and imprudent financial actions would eventually force the hand of governmental intrusion. Although governmental intrusive actions usually appear to be reactive, these do have salutary and serious impact on the corporate sector.

Modern business organizations have to be more mindful of all its stakeholders and the general public than did their counterparts just a half a century ago. Stockholders are no longer the only group to satisfy. Board of directors is made more accountable to corporate conduct, in addition to the corporate executives. Businesses in the modern day are not only responsible to their owners but also to the larger society. The stakeholder approach focuses on the widespread societal accountability, or at least some satisfying answerability, of the top management of a corporation. Corporation size is an important consideration in the scope of answerability. Thus, the larger corporation is, the larger are its responsibilities and the greater the potential for good or damage to the larger society, and consequently, the greater conspicuity to which it bares itself.

\subsection{Hierarchical Considerations of Business Ethics and Social Responsibility}

Business organizations are legal, economic and social entities with specific business goals, strategies and activities. In that a business organization has to be intensive in its goal directed activities (Goodman and Arenas, 2015). In this way it can satisfy the economic expectations of its stakeholders. It is expected to achieve the economic performance in the given economic, competitive and other conditions in which it operates. Business and society have special relationship and bond. A for-profit or a non-profit organization is a social organ with business and economic objectives. It operates within a society. Also, there are varying values and standards for a large MNC which would have many foreign subsidiaries in different countries, and, the host countries of the foreign subsidiaries would have varying expectations and standards for corporate behavior. So, in such cases it must reflect the higher ethical ideals of the society as it conducts its organizational activities. Otherwise, the society would not so happily support it even though many of the people buy and use its products and services if the organization is an efficient producer. Its economic and technical excellence alone will not absolve it if it has unacceptable CSR activities. While the detailed ethical values, practices and 
priorities are culture-bound, there are basic core ethical values that are common to many cultures, with varying priorities and methods of implementation. Global organizations may need to have a set of generalized core philosophy and values for its entire global organization, while allowing its individual foreign operations to develop detailed CSR goals and activities to match valid local expectations.

\section{Literature Review}

The literature review ranges from a focus on pure profit objectives that are solely focusing on the corporation's responsibility to stockholders. On the one end of the spectrum is the Milton Friedman school of thought of the single-minded pursuit of profit maximization and responsibility to the stockholders. On the other end of the spectrum is a more liberal and generous focus, that of an organization focusing upon both internal economic performance, as well as, the expected external contributions to the society. The wide range of spectrum provides an organization with a strategic choice perspective.

\subsection{Current Conceptualization of Hierarchy of Business Ethics and Social Responsibility}

The following provides an oft quoted hierarchy of business ethics and social responsibility. It can provide with a combination of the internal and the external organizational expectations of an organization.

Archie Carroll (1991) provides a hierarchy of responsibilities for an organization, as in the following:

"Level 4: Philanthropic responsibilities

Level 3: Ethical responsibilities

Level 2: Legal responsibilities

Level 1: Economic responsibilities."

In this context, it may be observed that the public and stakeholder expectations have gone up. They have rising expectations such that organizations have to be ever more vigilant to pursue the priority system as in the following with the wide spread use of social media and the ever observant journalists, organizations have to be not only careful but also pursue greater transparency and better internal training and communication.

\subsection{Proposed Hierarchy of Business Ethics and Social Responsibility}

There may be another priority or hierarchical system. The paper proposes one such system. A general priority system of organizational conduct, as expected by the public and its stakeholders, may be delineated as in the following:

Philanthropic responsibility

Being honorable: Over and above the call of ethics and legal

Economic responsibility

Ethical responsibility

Legal responsibility.

It is imminent that future expectations will exact higher standards as expectations of the public and stakeholders rise globally. The rising conscience of the public and stakeholders would place greater expectations on organizations to perform with a purer organizational conscience.

It is argued in this approach that, for an organization as a self-contained unit within its society to perform acceptably, it must first perform economically in a sound manner. It must first generate an acceptable profit so that it meets its financial obligations to its stockholders. This solid economic performance is needed for it to be a good social responsible corporation.

\subsection{Other Hierarchies and Perspectives of Business Ethics and Social Responsibility}

There is a wide variety of priority system or hierarchy of responsibilities, as observed before. CSR takes different forms for different people. There are based upon different conceptual foundations, values and assumptions. Depending on the choice of CSR, it can have far reaching consequences on corporate conduct. As it can be expected different scholars have different views and concepts, making for a wide range of views and intensity of values. These scholars include: Ali and Aali, 2015; Alzola (2015), Asgary \& Mitschow (2002), Brady, Crittenden, Hoffman \& Robertson (2002), Cottrill (1990), Clikeman (2004), Donaldson (2003), Freeman \& Gilbert (1988), Duska, 2014; Freeman \& Liedtka (1991), Goodman and Arenas (2015), Grant (1991), Kim, Monge and Strudler (2015), Kraft \& Hage (1990), Salbu (1993), Saunders \& Thorne (2002), Snider (2003), and Stoffman (1991); Tlaiss, 2015. Their arguments are further explained in the following paragraphs. 


\subsection{The Wide Spectrum in Perspectives of Business Ethics and Social Responsibility}

It may be pointed that several of them have recurring or similar themes with varying interpretations and approaches. They suggest varying gradations of CSR intensity, from Milton Freidman-like economic pursuit to modest profit intensive priority mix, blended with high social responsibility orientations (Friedman, 1962). Many scholars agree that firms must pursue some form of careful and responsible corporate conduct and worthwhile social responsibility activities. They have several divergent perspectives regarding the combinations of their directions and priorities. Some scholars emphasize that the ethical conduct must be considered as an iron-clad requirement corporate giving and social responsibilities programs (Alzalos, 2015; Armstrong, 2003; Asgary and Mitschow, 2002; Brady et al 2002; Donaldson, 2003; Epstien, 1987; Kim, Monge and Strudler, 2015). Other scholars believe in the importance of adopting the stakeholders approach as a pivotal concept for developing effective social responsibilities activities (Cottrill 1990). Furthermore, some others go over and above, a step beyond and state that strategic management must first start with a strong moral core (Ali and Al-Aali, 2015; Alzalos, 2015; Epstien, 1987; Freeman and Gilbert, 1988; Kim, Monge and Strudler, 2015; Kraft and Hage, 1990; Tlaiss, 2015).

There is the stronger counter current to the Milton Friedman school of thought which is that firms should single-mindedly serve the stockholders and that for-profit firms should not at all pursue social responsibilities (Friedman, 1962; Grant 1991, Stoffman 1991). Also, for international business, some scholars cite the cultural gap and divide as a major challenge for global firms to formulate effective global social responsibilities programs and goals (Alzalos, 2015; Asgary and Mitschow, 2002; Brouthers and Brouthers, 2001; Kim, Monge and Strudler, 2015; Saunders and Thorne, 2002; Snider, 2003; Wozniak, 1997). These assumptions and concepts point to the greater need for a comprehensive approach to global social responsibility and socially responsible corporate conduct that are based on a fundamental more base and that economically well performing firms must give back to society just as they get from the resources and revenues from the society.

This wide range, along with alternative and varying methods of social responsibility action, can be sustainable only if the organization is consistently performing profitably. Implicit in the sustainable concept is that an organization must show at least a reasonable growth. Growth may be manifested in terms of growth in sales revenues, market shares, product innovation and augmentation, product range expansion, target market segment expansion, product application enlargement, organizational development and career development of its employees, improved competitiveness, and sustained total quality management. Organizational growth and improving profits are interrelated. So too are profits and sustainable social responsibility.

These issues generate a perspective about an organization in that it must harmoniously co-exist in the society. It must respect the values and expectations of the society as it pursues its economic goals. These views are supported by Freeman and Gilbert (1989, p. 89) when they state:

"Firms are social entities, and so they should play a role in social issues of today. They should take seriously their 'obligations to society' and actively fulfill them."

The application here of the stakeholder approach to the study of socially responsible corporate conduct is a worthwhile one. Scholars seem to use the stakeholder approach to facilitate social responsibility action. Epstien (1987, p. 104) states that the stakeholder approach is a cause-effect relationship between an organization's social responsibility and the effect upon its stakeholders. He views regarding the socially responsible corporate performance is to be viewed as:

"Relating primarily to achieving outcomes from organizational decisions concerning specific issues or problems which have beneficial rather than adverse effects upon pertinent stakeholders."

Moreover, an organization, including its foreign unit operating in its host country society, would perform better if it pursues the stakeholders approach to better integrate and coordinate the valid needs of all its stakeholders. Freeman and Liedtka (1991, p. 97) state in this context:

"If we come to see corporations as connected sets of stakeholders, all of whom are 'in it together', then we are able to live in a way that doesn't carve up the world into 'economic, social, political, and technological' parts."

As a continuation of the above argument, it may then be said that a global firm must satisfy its headquarters' stakeholders, and, all those of its foreign subsidiary units must simultaneously.

\section{The Models}

The models generate theoretical considerations about CSR, about an organization at its responsibilities to its society and its accountability to its government and its stakeholders. This implies that it should make concerted and sustained efforts to communicate, train and oversee its employees to be increasingly better at CSR. Improved CSR performances are wrought through the participation of the employees of the organization. The models provide some of the basic 
concepts regarding the fundamental ethical values, and, how an organization can effectively institutionalize them across its internal environment. This is even more important, and challenging too, for a diverse and globally spread out organization.

\subsection{Table 1}

It proposes the role of an "Ethics Advisory Board" (see the top left box) in exerting influences for a higher ethical and social responsibility conduct of all its employees in all decisions and actions conducted on behalf of the organization. These advisory board members are to be chosen from diverse backgrounds so that the board may exercise a more judicious approach and reflect a wider perspective of how an organization should fit in the context of its entire general and task environments in all of its countries of operations. The board should reflect a broad cross section of the society in which the organization exists.

The board should suggest to the top management the "ethical and socially responsible conduct". These are then to be applied in the organization's strategic management process, including the formulation and implementation of objectives, goals, corporate strategy, and operating tactics. Ethical values should be the bedrock of organizational activities.

The board is also an advisory entity to generate and ensure that a higher test that would be applied to all current and future proposed organizational long term objectives, goals, corporate strategy, specific strategies and activities. The focus should be to evaluate the consequences of each major choice or an alternative and to improve a plan for the chain of events that would follow the potential implementation of a given decision and choice.

\subsection{Table 2}

It presents a process for developing the guidelines of ethical conduct, their development and implementation. The organizational environments provide cues for the details of the formulation of strategies for the management of ethical issues for both, the organization's internal and external environments.

The focus is on trust, honesty, truthfulness and fair dealings with all parties. The bottom box presents the basis of developing an organizational ethical backbone through education, and, by setting the proper example.

The organizational general and task environments pose a significant pressure on its internal decision making and activities. This pressure tends to vitiate the clarity of ethical conduct. Thus, the emphases by the two lower boxes of the Table should be to create those correct and appropriate guidelines for ethical conduct and to pursue more ethical approaches and processes for the long term ethically acceptable performance.

\subsection{Table 3}

It presents the more applications-oriented details for ensuring that the organization would be ethical to all entities. These entities include: employees and unions, publics and community, customers and suppliers, ecology, and foreign subsidiaries. The approach here is that an organization must interact with its external environments in such ways that would benefit the environment. Thus, organization-environment linkages must be mutually beneficial and they must represent higher level ethical conduct. Also, over a period of time an organization must contribute to the society in meaningful ways that address the important concerns of the societal needs.

\subsection{Conclusion on the Tables}

Emphasis should be for promoting integrity, trust, honesty and fair dealing in all activities of the organization. The ethical conduct guidelines are then the purview of the middle and lower level management through the creation and use of guidelines for the common practices of the organization as it conducts its normal business activities. Business ethics and social responsibility are interrelated. An organization must first address its ethical component and then address, as the Harvard Business School strategic management professors refer to as, "its acknowledged obligations to segments of society other than stock holders".

\section{Conclusions and Recommendations for Actions}

\subsection{Important Conceptual Considerations in Business Ethic and Social Responsibility}

Ethical and social responsibility values should guide an organization's actions because an organization is rooted in its society. A society provides an organization: (a) the very basis of its existence, (b) its sustenance, and (c) the scope for its future survival, profitability and growth. Therefore, an organization must comply with the society's expectations of its conduct, and, its construct of acceptable business ethics and social responsibility. Moreover, it must continuously keep exceeding the society's expectations of what may be legitimately claimed to be the obligations and responsibilities of a well performing, profitable organization.

In the case of an MNC or global organization, the social responsibilities goals and strategies would depend upon a foreign subsidiary's host country needs and expectations, and, overall MNC's and foreign unit's resource capabilities. 
This issue is important in determining the sustainability and scope of social responsibilities goals and strategies. The stakeholder approach is important. Stakeholders of the MNC as a whole, and, those of each foreign subsidiary unit are together important in this regard. The synthesis of the needs of all stakeholders at both levels (the MNC's HQ level, and, the foreign subsidiaries' level) should be considered in the formulating the business ethics and social responsibility objectives, goals and strategies.

Social responsibility is culture bound. Thus, each host country culture and values must determine the specific, detailed social responsibilities goals, strategies and programs. The overall social responsibilities framework of the MNC is important. It must reflect the broad trends and changes in the social fabric of the world as a whole. While this overall, global MNC framework should be guidepost, the host country culture and social responsibilities expectations and needs must be the drivers of a foreign unit's social responsibilities goals and strategies.

The level of host country's governmental and civic services and social programs should also be helpful in determining the scope, extent and content of a foreign unit's social responsibilities programs. At the same time, these programs must be consistent with the foreign unit's and MNC's resource capabilities and profit performance.

When a particular foreign subsidiary's host country's ethical and social responsibility standards are higher than those of the MNC's home country, then it would an expectation that the foreign subsidiary would strive to meet and exceed the higher standard. This would, in turn over a period of time, stimulate the rest of the MNC organization to achieve the higher standard.

The hierarchical preference scheme, starting with the legal and ethical, economics, and then to the decent or, honorable and philanthropic and socially responsive conduct is a good scheme. It is implicit that an organization would strive to climb upwards in this hierarchical scheme. An organization's management must strive to steer its employees to achieve a rising standard as it continually adjusts to the larger society's needs.

A multi-dimensional stakeholder approach is an organized way of achieving a desirable and equitable or balanced way of pursuing CSR. This appears to have a better chance of serving most needs of the organization's stakeholders in an equitable manner.

Corporate Social Responsibility (CSR) is now an accepted phenomenon. It is now a given in the corporate scenery. An organization must establish a high level of trust and respect in the eyes of its immediate society and in the regional and international society at large. Non-compliance of CSR is no longer an option.

Compromising CSR can have serious consequences. Legal and ethical compliance is an absolute must. However, by merely pursuing the barest of legal and ethical conduct will not suffice in the long run in the case of a well performing, profitable organization. There is a growing stakeholder and public expectation that corporate conduct would fully embrace decent and honorable activities. Good economic performance would also require philanthropic and socially responsive activities.

\subsection{Strategic Management and Business Ethics and Social Responsibility}

Strategic corporate social responsibility planning should be an integral part of the strategic management of an overall MNC organization. Business ethics and social responsibility should be regarded as the starting point of any organization's strategic management process, and not added as an after-thought. Such a sound principle of strategic management approach and process would serve an organization very well in the long run. In this way, its meaningful enactment of its social environments would better integrate it with the society. The society in such a case would better regard and value the organization than if it did not enact the social environment. Such an approach would engender higher trust and bond between an organization and the society. 
Table 1 Business Ethics and Social Responsibility as Integral Parts of the Strategic Management Process

\begin{tabular}{|l|}
\hline $\begin{array}{l}\text { Ethics } \\
\text { representatives from categories of: }\end{array}$ \\
- \\
- Social, welfare services \\
- Industry specialist (from outside) \\
- Company's employees from \\
different levels/parts \\
- Unions \\
Top Mgmt official, representing \\
executive mgmt \\
Banking officials, CPAs, lawyers, \\
professors, technical or mgmt \\
consultants, retired govt'al \\
executives
\end{tabular}

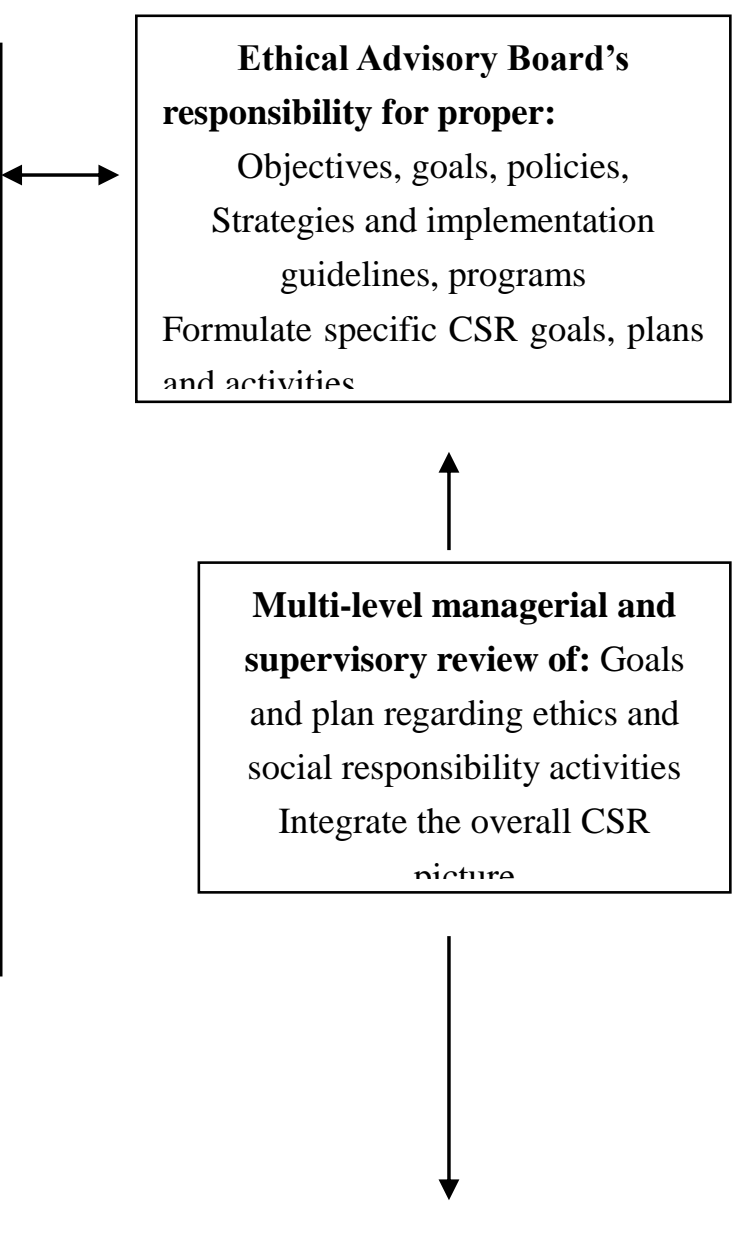

\section{Separate and additional reviews by} line and staff personnel:

Top level executives

Middle level executives

Lower level executives

Supervisors

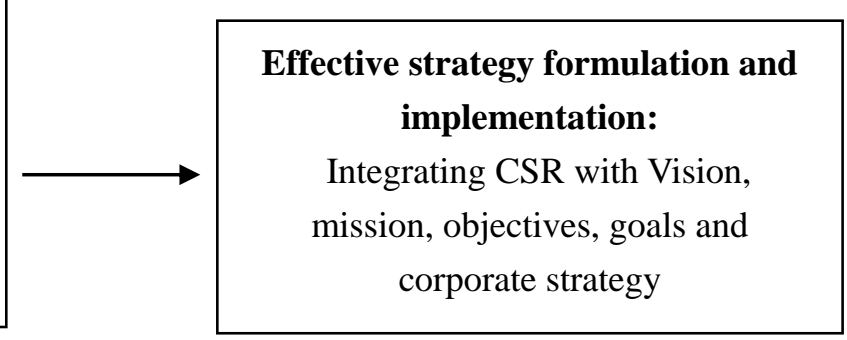


Table 1. Description: Business ethics advisory board has a strong influence in ensuring the CSR plans formulation process. Growth in the organizational activities and competitive pressures are blended with CSR values.

Table 2 Formulating and implementing Ethical Behavior Guidelines

\section{Review of the major factors and trends in the general and task environments of the organization, such as:}

Marketing, supplier, social, local, general economy, governmental, legal, industry

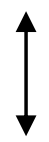

\section{Major Guidelines for Ethical Activities For:}

1. Organizational:

- Fair HRM practices regarding employees: recruitment, promotion, layoffs, career development and training, fairness and considerateness in dealing with employees

- Vigilance over and mentoring of employees regarding ethical behavior on issues such as: bribery and other unfair practices in dealing with customers, dealers, suppliers, government, ecology, patents, technical safety

- Vigilance over, mentoring of employees regarding issues such as: sexual harassment prevention, and, dealing with minorities, women, handicapped, new employees

- Continuous education of all employees about the above

\section{Environmental:}

- Honesty, integrity and trust in dealing with external stakeholders and general public

- Networking with external stakeholders \& other external segments to develop newer ethical

\section{Major Approaches for Effective Ethical Activities regarding the:}

- Support from all parts of the organization for ethics

- Communication and mentoring and training on ethics

- Overseeing of the activities on ethics

Table 2 Description: Organizational task environments are important to elicit basic cues of the organization's future activities. However, these cues must be blended with important ethical values and considerations for steering the organization's course along acceptable paths.

Table 3 Guidelines for Implementing Ethical Social Responsibility Activities

The formulation of guidelines for fair and ethical activities, on such issues as:

HRM practices, particularly related to: Women, minorities, sexual harassment prevention, recruitment, training, career development and promotion

Transparency, integrity, truth and good faith, trust worthiness in all transactions with all stakeholders on issues such as: Potential dangers of company's operating activities, such as industrial accidents issues, Product safety issues and disclosures, fair and truthfulness in advertising, product usage cautions, Supplier relations and suppliers' industrial safety, and, product/component safety standards

Customers: Product safety issues disclosures, fair and truthful advertising, product uses and product use instructions, 
proper customer education for safety and greater customer satisfaction

Environmental responsibilities: Improving technologies, training and practices for environmental safety

Overseas activities: Ethical and social responsibility conduct in all overseas activities and nteractions that would generate a higher level of respect from all constituencies.

Table 3 Description: An organization should have an established code of conduct for ethical behavior. Further, it should also have an established set of guidelines for ensuring that important practices that touch sensitive aspects are properly formulated and promulgated to all organizational members.

\section{References}

Ali, A., \& Al-Aali, A. (2015) Marketing and ethics: What Islamic ethics have contributed and the challenges ahead. Journal of Business Ethics, 4(29), 833-845. http://dx.doi.org/ 10.1007/s10551

Alzola, M. (2015).Virtuous persons and virtuous Actions in business ethics and organizational research. Business Ethics Quarterly, 3(25), 287-318. http://dx.doi.org/ 10.1017/beq.2015.24.

Armstrong, M. B. (2003). Professionalism and ethics in accounting education. University of Montana.

Asgary, N., \& Mitschow, M. C. (2002).Toward a model for international business ethics. Journal of Business Ethics, 36, 239-246.

Brady, Michael K., Crittenden, William F., Hoffman, James J., \& Robertson, Christopher J. (2002). Situational ethics across borders: A multicultural examination. Journal of Business Ethics, 38, 327-338.

Brouthers, K. D., \& Brouthers, L. E. (2001). Explaining the national cultural distance paradox. Journal of International Business Studies, 32, 177-195.

Carroll, A. B. (1991). The pyramid of corporate social responsibility: Toward the moral management of organizational stakeholders. Business Horizons, 34, 39-48.

Carroll, A. B. (1999). Corporate Social Responsibility. Evolution of a definitional construct. Business and Society, September. http://bas.sagepub.com/content/38/3/268.short?rss=1\&ssource $=\mathrm{mfc}$

Clikeman, P. (2004).Socially conscious corporation: How can you reap the rewards of good corporate citizenry? Strategic Finance, 23-35.

Cottrill, M. T. (1990). Corporate social responsibility and the marketplace. Journal of Business Ethics, 9, 723-728.

Donaldson, T. (2003). Editors comments: Taking ethics seriously - A mission now more possible. Academy of Management Review, 28, 363-378.

Duska, R. F. (1990). Why business ethics needs rhetoric: An Aristotelian perspective. Business Ethics Quarterly, 1(24), 119-134. http://dx.doi.org/ 10.5840/beq2014233

Epstien, E. M. (1987).The corporate social policy process: Beyond business ethics, corporate social responsibility and corporate social responsiveness. California Management Review, 24, 99-111.

Freeman, R. E., \& Gilbert, D. R. (1988). Corporate strategy and the search for ethics. Englewood Cliffs, NJ: Prentice Hall.

Freeman, R. E., \& Liedtka, J. (1991). Corporate social responsibility: A critical approach. Business Horizons, $34,92-97$.

Friedman, M. (1962). Capitalism and Freedom. Chicago: University of Chicago Press.

Goodman, J., \& Arenas, D. (2015). Engaging ethically: A discourse ethics perspective and social shareholder engagement. Business Ethics Quarterly, 2(25), 163-189. http://dx.doi.org/ 10.1017/beq.2015.8

Grant, C. (1991). Friedman fallacies. Journal of Business Ethics, 10, 907-913.

Kim, T., Wan, M. R., \& Strudler. (2015). Bounded ethicality and the principle that "ought" and "can". Alan. 2015. Business Ethics Quarterly, 3(25), 341-361. http://dx.doi.org/ 10.1017/beq.2015.25

Kraft, K. L., \& Hage, J. 1990. Strategy, social responsibility and implementation. Journal of Business Ethics, 9, 12-18.

Salbu, S. R. (1993) Corporate social responsiveness: Choosing between hierarchical and contractual control. Journal of Business Ethics, 12, 27-35.

Saunders, S. B., \& Thorne, L. (2002). The socio-cultural embeddedness of individuals' ethical reasoning in organizations (cross-cultural ethics). Journal of Business Ethics, 35, 1-14.

Snider, J. (2003). Corporate social responsibility in the $21^{\text {st }}$ century: A view from the world's most successful firms. 
Journal of Business Ethics, 48, 175-186.

Stoffman, D. (1991). Good behavior and the bottom line. Canadian Business, 28-32.

Tlaiss, H. (2015). How Islamic business ethics impact women entrepreneurs: Insights from four Arab Middle East countries. Journal of Business Ethics, 4(129), 859-877. http://dx.doi.org/ 10.1007/s10551-014-2138-

Wozniak, L. (1997). International business ethics: When a corporate code of conduct is NOT enough. Relocation Journal, 1-28.

\section{(c) $\mathrm{EY}$}

This work is licensed under a Creative Commons Attribution 3.0 License. 